\title{
The Role of External Auditors in Detecting and Reporting Corporate Fraud in Public Listed Companies in China
}

\author{
Yuhao Zhou \\ Accounting School \\ Dongbei University of Finance and Economics \\ Room 1705, Unit L, Building 27 \\ Zhishuyuan, Shahekou District \\ Dalian City, Liaoning Province \\ China, 116023
}

Tel: +86-136-108-586-67Ｅ-mail: imzhouyh@163.com

Received: November 16, 2011

doi:10.5430/ijba.v3n1p2
Accepted: December 12, 2011 Published: January 5, 2012

URL: http://dx.doi.org/10.5430/ ijba.v3n1p2

\begin{abstract}
With only 30 years development of Chinese capital market, especially the listed companies and audit profession, there are still some deficiencies compared to the UK which limits the role of external auditors. With the comparisons in the legal and regulatory framework governing external auditors and the responsibilities of external auditors in detecting and reporting corporate fraud between the UK and China, these differences can reflect some difficulties for Chinese auditors in detecting and reporting corporate fraud. Hence, semi-structured interviews are conducted to collect information about the practical difficulties in their audits of listed companies in detecting and reporting fraud in China. In order to strengthen the role of Chinese auditors in detecting and reporting corporate fraud, some recommendations are made finally.
\end{abstract}

Keywords: External Auditors, Corporate Fraud, Chinese Public Listed Companies

\section{Introduction}

\subsection{Background}

China's economic reform started in late 1978 when the central government launched a long-term economic development program. At the heart of the program were the twin strategies of economic reform and opening-up the economy to the outside world. Since the commencement of economic development, China has undergone significant economic and social changes. Between 1979 and 2007, China's gross domestic product (GDP) grew at an average of more than 9\% annually and by 2008 China had become the fourth largest economy in the world (CSRC, 2008).

China's economic growth has been accompanied and, to an extent, facilitated by the development of China's capital market. In December 1990, two stock exchanges were established successively, namely the Shanghai Stock Exchange (SSE) and the Shenzhen Stock Exchange (SZSE). By the end of 1991, the Shanghai Stock Exchange had eight listed stocks while the Shenzhen Stock Exchange had six listed stocks (CSRC, 2008). Since then they have developed at a tremendous pace and, by the end of 2008, there were 908 stocks and 864 companies listed on the Shanghai Stock Exchange (SSE, 2009) and 782 stocks and 740 companies listed on the Shenzhen Stock Exchange (SZSE, 2008).

The importance of public listed companies (plcs) as a component of China's economic system is reflected in the fact that, by the end of 2007, the market capitalization of listed companies in China reached US\$4.5 trillion, equivalent to about $132.6 \%$ of China's GDP(CSRC, 2008). In 2007 the total funds raised through Initial Public Offering (IPO) alone reached US\$62.9 billion, the greatest amount of funds raised by this means in any country in the world (CSRC, 2008). The importance of China's capital market is also reflected in the fact that, in 2007, the daily trading volume averaged US\$26.1 billion (CSRC, 2008). The rapid growth and importance of listed companies in China is reflected in Figure 1.

China's capital markets have gradually developed into a marketplace whose legal system, trading rules and regulatory frameworks are increasingly aligned with international standards and principles (Chen, 2008). The adoption of international standards and principles had stimulated the rapid development of public listed companies. This 
development has, in turn, been accompanied by a demand from investors, especially international investors, for reliable financial information. However, the evidence suggests that, in many cases, the annual financial statements published by these companies are not reliable and fraudulent financial reporting is widespread. For example, between 1996 and 2007, 461 enforcements of information disclosure were issued by the China Securities Regulatory Commission (CSRC) and the two stock exchanges. Of these, 134 (29.1\%) were related to fraudulent financial reporting (SSE, 2008). During the period 1996-2002, 72 enforcements were directly linked to fraudulent financial reporting. According to a report of the National Accounting Institute (NAI), in 2005 the ten largest corporate fraud cases in China involved more than US\$300 million (NAI, 2006).

Two particularly notable examples of fraudulent financial reporting are those of Hainan Minyuan and Yin Guangxia. In 1996, the stock price of Hainan Minyuan rocketed by $1059 \%$ following its reporting of a huge increase in income which proved to be fictitious. In 1997, this company was investigated for false accounting and, in that year, its shares were suspended from trading. The investigation found that US\$79 million of the capital reserve and US\$68.1 million of US\$68.7 million profits reported in the company’s 1996 annual financial statements were fictitious (CSRC, 2008).

Along similar lines, in 2001, Yin Guangxia was found to have announced US\$89.6 million of fictitious profits. It achieved these through fictitious purchase and sales contracts, export customs declaration forms, tax-free documents, financial bills, and value-added tax invoices during 1999 and 2000. The audit report issued by the Shenzhen Zhongtianqin Accounting Firm and its signatory accountants was held to be a gross misrepresentation. As news of the company's fraudulent financial reporting became known, the company's stock fell by the maximum permitted of $10 \%$ each day for 10 days. On May 25, 2005, the court ordered Yin Guangxia to compensate its minority shareholders by a total of 5.4 million shares (CSRC, 2008). The license of the Zhongtianqin Accounting Firm was also revoked by the Ministry of Finance (MOF) (MOF, 2005).

In 2003, the NAI conducted research to ascertain the opinion of the chief financial officers (CFOs) of 216 companies regarding the reliability of the annual financial statements of public listed companies in China. It found that $70 \%$ of the CFOs considered the financial statements to be unreliable; further $8.04 \%$ regarded the financial statements to be absolutely unreliable. Only $2.5 \%$ of the CFOs were of the opinion that the financial statements of Chinese Plcs are reliable and the remaining 9.5\% of the CFOs were undecided about the financial statements' reliability (NAI, 2003). Despite great improvements in audit quality in China in the past 30 years, a substantial number of instances of fraudulent financial information are still reported (Xuan, 2002). In 2001 alone, more than 100 Chinese listed companies were investigated by CSRC or received public condemnation by the SSE or SZSE. Most of these cases were related to accounting cheats (Lei, 2009).

In spite the great development of Chinese capital market, there are some overwhelming problems. Currently, in China's capital market, the listed companies have a unique ownership structure. The major shareholders are usually the state and quasi-state institutions. On average, about $30 \%$ of the listed companies' shares are owned by the state (central government), its ministries, and local and regional government. Another $30 \%$ of the shares are owned by legal entities most of which are ultimately owned by the state (Chen et al., 2005). Overall, Government entities effectively own more than $50 \%$ of the stock of $85 \%$ of the listed companies (Mark et al., 2000). At the end of 2000, only 36\% of companies' shares listed on the SSE and SZSE belonged to individual shareholders in the total 374.628 billion shares. 37\% were state-owned shares and the remaining $27 \%$ were owned by other legal entities (Thomas, 2004). In the end of 2005, $61.36 \%$ of the total shares were non-tradable shares in which $85.69 \%$ were belong to the promoters (Kang, 2007) that is to say many of the listed companies are basically controlled by the state. In 2004, in northeastern China, the state still owned or controlled a majority interest in appropriately 90\% of all enterprises (Evince, 2007). Meanwhile, the administrative color of corporate governance structure in listed companies is strong. The senior management of a large number of Chinese listed companies as government staffs not professional managers has a strong intention to get promoted by good work performances which focus on the protection and increase of the value of state-owned assets. Meanwhile, government owners have strong incentives to pressure management to report favorable earnings, but little demand for independent audit (Mark et al., 2000). In China, the development of corporate governance is also extremely young. Thomas W. Lin (2004) argued that many problems still widely exist in corporate governance in China: weak internal control, disregard shareholders' rights, frequent insider trading, self-dealings and collusions in market manipulations, accounting cheat, weak independent board of directors and specialized committees, weak supervisory board and weak auditing profession. A survey conducted by Deloitte China in 2008 about the current situation of application of internal control among listed companies. 57\% of respondents held an opinion that the management was lack of strong sense of the internal control to initiate and sustain it (Deloitte China, 2008). 
With the development of the Chinese capital market and more widespread investment in the listed companies (especially by foreign investors), the independent auditing of the companies' financial statements has become increasingly important. After the founding of People's Republic of China (PRC) in 1949, the Central Government started the socialist transformation of capitalist industry and commerce in 1953. With the completion of this transformation at the end of 1956, a highly-centralized planned economic system of the Soviet mode was established (Audit, 2003) and auditing by public accountants was abolished (Gensler \& Yang, 1996). However, with the economic reform which commenced in 1978, The Law of the People's Republic of China on Chinese-Foreign Joint Ventures was released in July 1979 (NPC, 1979) and moreover Provisions of the State Council for the Encouragement of Foreign Investment were issued by the State Council in 1986 (State Council, 1986). Foreign investment in China was permitted and it increased rapidly as reflected in Figure 2. By 2009 China ranked the first among developing countries in attracting foreign investment and had done so for 17 consecutive years (MOFCOM, 2009).

As indicated above, the inflow of foreign capital created the demand for external audits by foreign investors who wished to be assured that the financial statements of entities in which they invested were reliable. The demand for external audits also resulted from the Income Tax Law for Sino-foreign Joint Ventures which was issued by the National People's Congress (NPC) in September 1980 (NPC, 1980). And the MOF's Detailed Principles for implementation of Income Tax Law for Sino-foreign Joint Ventures issued in December 1980 which explained how the law should be implemented (MOF, 1980). Among the principles, article 20 specified a statutory requirement only for Chinese-foreign joint ventures' financial reports to be signed by Chinese auditors for tax collection purposes. Shortly after that, in order to clarify the legal status of accounting firms, the MOF (1980) issued Provisional Regulations Concerning the Establishment of Accounting Consultancies. This resulted in accounting firms beginning to emerge to offer relevant services to Chinese-foreign joint ventures. This was regarded as a signal of the recovery and reconstruction of the Chinese public accounting (Chen, 2005). The provisions required the establishment of new accounting firms to be sponsored by a government agency. Additionally, the foreign accounting firms according to provisions, foreign must operate their business in the form of Sino-foreign joint ventures. By the end of 1988, there were more than 200 Chinese accounting firms and 2000 certified public accountants (CPAs) (CICPA, 2008).

As economic reforms continued in China, the state owned enterprises started going private, ownership and management of the privatized companies became separated and the Chinese capital market began to develop. These changes resulted in the government recognizing a greater need for the auditing profession to ensure reliable financial information. In the light of this need, The Chinese Institute of Certified Public Accountants (CICPA) was founded in November 1988. This was the first professional accounting body founded in China since the establishment of the PRC in 1949. The mission of the CICPA, with the construction of professional credibility and integrity as its guiding principle, is to provide services to its members; to monitor the service quality and professional ethics of its members; to regulate the CPA profession according to relevant laws; to coordinate the relationship within and beyond the CPA profession; to protect the interests of the general public and the legitimate rights of the CICPA members; and to promote the healthy development of the CPA profession (CICPA, 1995).

In October 1993 the 4th Meeting of the Standing Committee of the Eighth National People's Congress adopted the Law of the People's Republic of China on Certified Public Accountants (CPAs Law). This law took effect on January 1, 1994 (NPC, 1993) and has not been revised subsequently after this law was adopted. The number of Chinese accounting firms and CPAs increased rapidly and by the end of 1993 there were 2400 Chinese accounting firms and 10000 Chinese CPAs (CICPA, 2005); by the end of 1997, this had increased to 6900 accounting and auditing firms and 62,460 practicing CPAs (Tang, 1999).

Additionally, when China joined the world trade organization (WTO) in 2000, the Chinese government promised to repeal the requirement for foreign accounting firms to hold joint venture licenses with Chinese firms in 2012 (MOFCOM, 2005). In order to support domestic accounting firms in the pace of a potential increase in competition from foreign firms, in 2009, the State Council issued a policy statement ([2009] No. 56) which stressed the need to vigorously develop competitive home-grown accounting firms. The central government's plan is to develop about 10 large and 200 medium sized domestic accounting firms over the next five years which will be able to compete with the foreign firms (Chen, 2009). Following the policy statement, the CICPA announced specific measures to help China mainland firms grow "bigger and stronger" by giving them support in terms of, for example, staff training and market opportunities (A PLUS, 2010). However, firms had to be selected to be assisted to develop. In 2009, the MOF and CSRC introduced a scheme where they selected some auditing firms which achieved an operating more than RMB 300 million in 2008 and two thirds of this income from auditing as a primary requirement to audit companies listed in Hong Kong. 
In announcing this policy, the Vice Minister of the MOF explained "A policy restricting some firms from doing some businesses is not consistent with free market rules. But because the mainland accounting firms are at varying development stages, we also cannot let all of them participate in international business.” In China the government plays a dominant role in the economy and the firms selected for government support should grow and develop rapidly. The small and medium size firms get the opportunity but involve themselves in a more intense competition at the same time.

After nearly 30 years development, by 31 May 2006, the number of accounting firms had increased once more - to 5 600. At this time there were also more than 69700 practicing CPAs.

\subsection{Research Methodology}

In order to achieve the research objectives, the following methods have been employed:

\subsubsection{Literature Review}

Academic and professional articles relating to corporate fraud and the responsibility of external auditors in both China and the UK to detect and report corporate fraud have been reviewed. These were be identified by inputting key words such as 'corporate fraud,' and 'responsibility of external auditors in China and in the UK' into databases such as JSTOR, EBSCO EJS and Business Source Premier for literature in English and WANFANG, CNKI for literature in Chinese.

\subsubsection{Document Study}

A study of International Standard on Auditing (ISA) 240: The auditor's responsibilities relating to fraud in an audit of financial statements, CSA 1141 : The consideration of auditor's responsibilities relating to fraud in an audit of financial statements, which specify, the auditors'responsibilities for detecting and reporting corporate fraud in the UK and China respectively have been explained.

\subsubsection{Semi-structured Interview}

Semi-structured interviews have been conducted with eight employees in accounting firms in China to collect information on the practical problems faced by auditors in China in detecting and reporting corporate fraud and how these might be overcome.

\subsubsection{Deduction}

Recommendations for strengthening the role of external auditors of plcs in China in detecting and reporting corporate fraud have been deduced from the information derived from the literature review, document study and semi-structured interviews.

\section{The Legal and Regulatory Framework Governing the Responsibilities of External Auditors of Public Listed Companies in the UK and China}

\subsection{Legal and Regulatory Framework of External Auditing in the UK}

The UK is the place of origin of modern auditing. The Companies Act 2006 (CA 2006) requires all public listed companies to have their financial statements audited by a registered auditor. Such auditors may be either individuals, or firms with a majority of individuals, who holds a qualification of one of the six Recognised Qualifying Bodies (RQBs) and is registered with one of the five Recognised Supervisory Bodies (RSBs).

In the UK, ISAs which has a status of regulations were adopted by the Auditing Practices Board (APB). Currently, Financial Reporting Council (FRC) takes on the functions to as a unified and authoritative independent regulator. It charged the responsibilities by its operating bodies reflected in Figure 3. Under the oversee of FRC, the Institutes of Chartered Accountants in England and Wales (ICAEW) has established a Quality Assurance Directorate (QAD) to monitor the work of all of its members, including its registered auditors while the ACCA monitoring monitors the auditors registered with ACCA and APPA. And the audits of companies listed on the London Stock Exchange are conducted by the Audit Inspection Unit (AIU) of the Professional Oversight Board (POB). Meanwhile, the audits of companies listed on a stock exchange in the USA are under the monitor of USA's PCAOB besides RSB and AIU.

In a program named "the review and enlightenments of regulation model of CPAs in the UK" conducted by the CICPA in 2005, the CICPA describe the regulation model of the UK as a model consisted by legal authorization, government supervision and industry self-discipline (CICPA, 2005). It discussed the difference between two countries. High level of self-discipline is the most important characteristics in this kind of model, from the decentralized management of professional bodies in the early stage to the establishment of FRC by government and industry associations. These reforms has not weakened the self-discipline but strengthened the supervision at macroscopic level. 


\subsection{Legal and Regulatory Framework of External Auditing in China}

In China, the government regulation of CPAs is conducted in a comprehensive and multi-faceted way. There are several governmental regulators bodies which exercise supervisory authority including the financial department, audit authority, securities regulatory department, industrial and commercial administrative department, tax authority as well as the central bank, that is, the People's Bank of China (PBC). Of these, the financial department, audit authority and the securities regulatory department are the most important.

Prior to the first adoption of the "Independent Auditing Criterion for Chinese Registered Accountant" (IAC) in 1995, auditing guidelines in China were suggestive rather than prescriptive and lacked legal enforceability. With the deepening economic reforms since 1978, uniform professional standards were much needed. The CPAs Law (1993) composed on the CICPA responsibility for developing and implementing Audit Standards. However, they were only to be implemented by the CICPA once they were approved by the financial department of the State Council (CPA Laws, Article 35). In 1994, the CICPA was granted approval by the MOF to draft independent auditing standards that were aligned to international standards in auditing (ISAs). Only a few months after the issue of IACs, CICPA's China auditing standards board (CASB) was reorganized in order to increase the harmonization of Chinese auditing standards with ISAs to achieve improvements in audit quality. At the beginning of 2005, the MOF advocated a strategy of international convergence for both the Chinese accounting and auditing standards. Against this background, CASB adopted 22 new standards and revised 26 others. In 2006, Chinese Standards on Auditing (CSA) was released. This comprised 48 auditing standards that were greatly modeled on ISAs; they became effective on 1st January 2007. The current CSA is in line with ISAs except two standards reflecting the unique economic circumstances of China for which there are no equivalent ISAs (MOF, 2009). The CICPA plans to update the CSA with the ISAs so as to achieve full convergence by October 2010 (CICPA, 2009).

Resulting from the way in which CPA profession developed in China, the regulatory framework is quite different from that in the UK. In China the regulatory model of CPAs is a mixture of government management and professional regulation. As noted in Chapter 1, the demand for external auditors began in the early 1980s as a result of the inflow of foreign capital and the income tax law for Sino-foreign joint ventures. As also noted in Chapter 1, accounting and auditing firms had to be sponsored by a government agency or university as reflected in Table 1 . Additionally, with the establishment of the state audit administration (SAA) all CPA firms were subject to supervision by the financial and auditing departments of the government. When the CICPA was established in 1988, the professional body was delegated responsibility from the government to oversee and manage the accounting and auditing profession in China. However, in December 2002, the MOF re-asserted oversight responsibility for the accounting and auditing professions in China. As a result, the mixed regulatory model of CPAs in China established.

Business people and in particular foreign investors are concerned about the independence of Chinese auditors (Xiang, 1998). In 1998 CICPA started a program of restructuring the profession. The aim of the program was to separate the accounting firms from the state by disaffiliating the firms from their government sponsors and universities as well. This process was to be completed by an administrative order of the MOF by the end of 1999 (CICPA, 2005). After the restructuring, the number of accounting firms decreased from 6405 to 4805 as a result of dissolution or merger (Liu, 2008).

\subsection{The Differences in the Legal and Regulatory Frameworks of the Two Countries}

\subsubsection{The Responsibilities and Functions of Various Regulators are not Clearly Defined}

Owing to the lack of an effective coordination mechanism, the regulators operate independently in resulting somewhat happened. Repeated inspections, supervisions and checks on audit firms and auditors' work frequently emerge. Accounting firms are confused by the inconsistent, and some times conflicting, inspection requirements. And the frequent inspections are a real burden on the firms. Common about the situation was expressed by the CICPA in 2005 when it pointed out that cross-supervision and repeated inspection was one of the significant external factors which affected the healthy development of accounting firms (CICPA, 2005). In 2003, a survey of top 100 accounting firms conducted by MOF found that cross-supervision and repeated inspection was one of the greatest problems identified by the firms when asked about the government regulation. Seventy eight percent of the respondents identified that cross-supervision was existed and $60 \%$ reported that they had suffered from repeated inspection and cross-inspection. A further $59 \%$ expressed the view that inspection requirements of the different regulators varied and $33 \%$ expressed a similar view about punishment criteria (MOF, 2003).

\subsubsection{The Lack of Autonomy of the CICPA and its Local Branches}

The operations of the CICPA have the obvious administrative style, need to be reported to and approved by MOF. 
CICPA as vague status takes a limited role in the supervision system and then adversely affect its effectiveness. The CICPA is placed in the position where it plays a dual role: it must speak for the government and for its CPA members. This created a difficulty when there is conflict of interest between the government and the accounting/auditing profession. In this situation, the CICPA will fulfill its responsibilities to the government but neglect need of CPA members (Li, 2008). As an agency of MOF, it will always place the interests of the State first.

Its lack of autonomy discourages the CICPA from performing its functions. Although the CICPA carries out annual inspection of the professional services of CPAs as legally required to do so, its resources for this monitoring function are inadequate. In 2005, it had just 9 members for ordinary supervisory to inspect the professional services of many thousands of CPAs. At the local level, there may be as few as just one (Hu and $\mathrm{Bi}, 2005)$.

\subsubsection{The Independence Issue due to Former Sponsorship}

In 1999, Hao (1999) reported that government-affiliated firms constituted the dominant group and held more than $75 \%$ of the audit market in terms of number of clients. This brings handful of problems such as confusion of legal liability, ignorance of risk and sufficient potential threat to the independence of auditors. Likewise, local governments will ask the listed companies receive audits by firms in the same territory (Liu and Zhang, 1996).As a result, there is a lack of incentive for auditors to maintain independence (Lloyd Yang, 2003). With the further reform of ownership structure, the affiliated accounting firms adversely affect the quality of audit. In particular, foreign investors called for accounting and auditing services provided by non-government practitioners (Graham, 1996). The close relationship between accounting firms and their sponsoring Government agency resulted in audit engagements that were subject to frequent interventions by the Chinese Government (Lin \& Chen, 2004) and also affected auditors' responsibility to detect and report corporate fraud.

\section{The Responsibility of External Auditors for Detecting and Reporting Corporate Fraud in Public Listed Companies in the UK and China}

3.1 The Responsibilities of External Auditors of Public Listed Companies in Detecting and Reporting Corporate Fraud in the UK

Under ISA 240, an auditor conducting an audit in accordance with ISAs is responsible for obtaining reasonable assurance that the financial statements taken as a whole are free from material misstatement, whether caused by fraud or error (paras 5). They need to identify, assess and response to the risk of material misstatement due to fraud (paras 25-32). The objectives of the auditor are: (1) To identify and assess the risks of material misstatement of the financial statements due to fraud; (2) To obtain sufficient appropriate audit evidence regarding the assessed risks of material misstatement due to fraud, through designing and implementing appropriate responses; and (3) To respond appropriately to fraud or suspected fraud identified during the audit (paras 10).

For the characters of fraud, the standard required auditors to maintaining professional skepticism throughout the audit in detecting fraud. This can help the auditors in identifying and assessing the risks of material misstatement due to fraud. Meanwhile, maintains of professional skepticism can greatly assist the auditors in recognizing the possibility that a material misstatement due to fraud could exist (paras 8 \& 12).

The discussion on how and where the entity's financial statements may be susceptible to material misstatement due to fraud should be held to offer an opportunity for team members to communicate (paras 15).

If the auditor has identified or suspects a fraud, the auditor shall determine whether to report the occurrence or suspicion to the regulators. Although the auditor's professional duty to maintain the confidentiality of client information, it is the auditor's legal responsibilities to report such identified or suspected fraud.

\subsection{The Responsibilities of External Auditors of Public Listed Companies in Detecting and Reporting Corporate Fraud in China}

The first auditing standard related to fraud in China was IAC No.8: Error and Fraud (1996). This standard defines Chinese CPAs' legal responsibilities in respect of fraud. And it indicates that the detection of fraud is not part of the audit of a company's financial statements. Under this standard, the auditors generally held a passive attitude in relation to corporate fraud. However, since CSA 1141 The consideration of auditor's responsibilities relating to fraud in an audit of financial statements which is modeled on ISA 240 became effective on 1 January 2007, the position has changed. The new standard related clearly defines the auditor's responsibilities in respect of detecting and reporting fraud and the audit procedures that should be performed. Just follows ISA 240, CSA 1141 covers nearly all major items. 
3.3 The Differences of Responsibilities of External Auditors of Public Listed Companies in Detecting and Reporting Corporate Fraud in the UK and China

CSA 1141 basically consists with ISA 240. However, an important difference between CSA 1141 and ISA 240 is that examples of fraud risk factors included in the appendix of ISA 240 are not included in CSA 1141. Zhang (2007) argued that the fraud risk factors are omitted from CSA 1141 as the capital market for listed companies is totally different in China compared to western countries, so the fraud risk factors are not involved in current standards. And the research in fraud risk factors in China's listed companies is still immature and lacks authority as well as representativeness for fraud means in China are usually relatively simple and varied.

Meanwhile, the full implement of auditing standard become the key point in detecting and reporting corporate fraud. There are some special factors obstructing the implement of auditing standard to perform the responsibilities of external auditors in detecting and reporting corporate fraud in China. These factors are primarily cultural differences between the UK and China.

Patel (2002) argued that the independence of auditors may be affected by cultural background. Chinese culture has a higher power distance and lower individualism characteristics that are the weaker party will surrender to the stronger party easily. In an auditor-client relationship, the clients are in the more powerful position because they are responsible for hiring and dismissing their audit firms. Kenny (2008) argued that because of these cultural factors, the independence of Chinese auditors is more likely to be compromised than the independence of their UK auditors' counterparts.

In China, business transactions are relationship-based and a high premium is placed on the maintenance of harmonious interpersonal relationships and a high premium is placed on the maintenance of harmonious interpersonal relationships (Kenny, 2008). Business runs mainly according to relationships rather than disciplinary or other systems. Chinese listed companies seek to develop a good relationship with the auditors so as to acquire a satisfactory audit report. Because of the strength of interpersonal relationship auditors in China frequently find it difficult to comply fully with auditing standards and professional ethics. Consequently, auditors may not detect fraud that is likely to have been uncovered had auditing and ethic standards have properly followed. In this regard, it needs to be realized that users of audited financial statements have a very distant relationship with the company's auditors while that between the auditors and the company's management is significant and direct.

Another significant point is that at the core of Chinese traditional philosophy is "the doctrine of the golden" which means always keep neutral, or "the less trouble the better". Five of the interviewees expressed the opinion that this doctrine makes it difficulty for Chinese auditors to implement the standards to play their rightful role in detecting and reporting corporate fraud.

\section{Empirical Research: the Semi-Structured Interviews}

\subsection{Development of Question Guide and Overview}

The question guides including general topics associated to the real difficulties and some related issues in performing the role of external auditors in detecting and reporting corporate fraud in China are formed in advance of each interview. This is not an isolated process. The questions keep updating. Each interviewee gave some useful advice to perfect the question guides for the next semi-structured interview. The interview covers five main topics which are open and flexible:

Question (1) in practical work, what is the greatest difficulty you face in audits of Chinese listed companies in detecting corporate fraud or reporting any detected or suspected fraud? What are the reasons for the above difficulty in your opinion?

Question (2) what about other practical obstacles faced in your audits of Chinese listed companies in detecting and reporting corporate fraud? And why does that happen no matter personal reason or others?

Questions (3) do you familiar with the responsibilities specified in relevant laws, regulations and professional standards? Especially, how about your familiarity and the implement level of CSA 1141 which took effect on 1 January 2007? If the answer is negative, what is the reason?

Question (4) do you have any idea about differences between local accounting firms and international firms in processes in detecting and reporting corporate fraud? If any, why such differences exist? Do these differences reflect the special difficulties facing Chinese CPAs and local accounting firms?

Question (5) can you offer any suggestion to overcome these difficulties?

To facilitate the report and discussion of the results of the semi-structured interviews, the interviewees can be identified 
as follows:

$\mathrm{L}_{1}, \mathrm{~L}_{2}, \mathrm{~L}_{3}$ and $\mathrm{L}_{4}$ for the interviewees working in local accounting firms;

$\mathrm{B}_{1}$ for one interviewee working in a Big 4 firm;

$\mathrm{B}_{2}$ for a second interviewee working in a Big 4 firm who started her career from local accounting firms;

$\mathrm{F}_{1}$ for one interviewee currently working in a listed company in Hong Kong as an accountant once worked in a local accounting firm as external auditors of listed companies;

$\mathrm{F}_{2}$ for a second interviewee currently working as an official in a regulator once worked in a local accounting firm as assistant auditor of listed companies.

The profiles of these eight interviewees can be reflected in Table 2.

\subsection{Results of the Semi-structured Interviews}

\subsubsection{Responses to Question (1)}

In answering Question (1), all interviewees except $B_{2}$ regard the threats to the external auditors' independence as the greatest difficulty in their practical audits of Chinese listed companies in detecting and reporting corporate fraud.

The exposure of listed companies to corporate fraud, especially fraudulent financial reporting will result in serious, even disastrous consequences for the companies. Only if the auditors are independent from their listed company auditees will they carry out their audits without being influenced by auditees.

In explaining the threats to the independence of external auditors and exploring the reasons of the independence issue in Question (1), $\mathrm{L}_{1}$ mentioned that the firm he is working in currently was sponsored by the State-owned Assets Supervision and Administration Commission of the State Council (SASAC) before the restructuring in 1998. Meanwhile, some listed companies clients audited by this firm are also subordinate enterprises of SASAC. This kind of relationship weakens the independence of external auditors.

Meanwhile, four interviewees working both in small and large accounting firms stated that the managing partners of their firms started their career as government officials or university faculty. The managing managers have strong power in the firm. They could feel the pressure from their managing partners when carry on audits on listed companies whose management has some relationship with their managing partners.

Four interviewees working or once worked in small and medium sized firms expressed the view that domestic firms have little ability to withdraw pressure from their clients to keep independence. They stated that their firms have faced a sudden and significant increasing pressure in audit market as a result of a policy to support selected small and medium sized firms released in 2009. Two of them even receive clear information from the managing partners that the main goal is to guarantee the income of the firms to ensure the long-term development of the firms. The four interviewees conveyed that, during their audits of listed companies the possibility of losing the clients became evident. So that their firms could meet the income requirement to be selected to supported by the government to grow and develop rapidly because of the government's dominant role in the economy. Further, the worry of losing their listed companies clients who is the main source of income became greater. In an auditor-client relationship, the clients are in the more powerful position because they are responsible for hiring and dismissing their audit firms. As a consequence, these four interviewees admitted that they were unwilling to detect and report corporate fraud.

In addition to problems of being subjected to client pressure as a consequence of possibly losing clients, seven interviewees conveyed that they also found it difficult- for cultural reasons to withstand pressure from other parties in order to keep independence. This phenomenon was mentioned in Chapter 3. The independence of auditors may be affected by cultural background. The Chinese auditors are easy to surrender to other stronger parties. The answers of these seven interviewees have confirmed this point. They admitted that they are easily influenced by stronger parties such as the local government, their managing partners and clients.

A common threat to the auditors' independence mentioned by all interviewees, including $B_{1}$ who did not put the threats to independence as the first place in answering Question (1). As mentioned in Chapter 3, business in China usually base on relationship due to the Chinese culture. $\mathrm{B}_{2}$ said that foreign colleagues who came to work in China often experienced a culture shock for auditors in China have different work habits and styles compared with auditors in western countries. Seven interviewees pointed that they can easily be influenced by all kind of relationships. Meanwhile, they do not want to break any harmonious relationships, if do so, it will hurt their business career. These seven interviewees said that because of the strength of interpersonal relationship destroy their independence they frequently find it difficult to comply fully with auditing standards and professional ethics. Consequently, auditors may not detect fraud that is likely 
to have been uncovered had auditing and ethic standards have properly followed. In this regard, it needs to be realized that users of audited financial statements have a very distant relationship with the company's auditors while that between the auditors and the company's management is significant and direct.

\subsubsection{Responses to Question (2)}

In answering Question (2), five interviewees mentioned the difficulty from Chinese listed companies resulted from poor corporate governance. As mentioned in Chapter 1, Chinese listed companies have a high degree of shareholder concentration. Five interviewees identified that among the listed companies as their clients, their major shareholders are usually the state and quasi-state institutions especially in important industries. Four interviewees said that administrative styles are obvious in the operation of listed companies for the highly concentration of ownership of states.

In accordance with CSA 1141, the risk of not detecting a material misstatement resulting from fraud is higher than the risk of not detecting one resulting from error. This is because fraud may involve sophisticated and carefully organized schemes designed to conceal it, such as forgery, deliberate failure to record transactions, or intentional misrepresentations being made to the auditor. The auditor's ability to detect a fraud depends on factors such as the skillfulness of the perpetrator, the frequency and extent of manipulation, the degree of collusion involved, the relative size of individual amounts manipulated, and the seniority of those individuals involved. Furthermore, the risk of the auditor not detecting a material misstatement resulting from management fraud is greater than for employee fraud.

Because of the common interest of management, management is motivated to bias the financial statements together so that they reflect well on their performance. Management especially the senior managers would prefer any fraud found in their companies after their term in office has come to an end. Hence, they will try to keep hidden any fraud which is found to exist, leaving such a tough problem to their successor, avoiding affecting their own official career.

Still in answering Question (2), five of the interviewees mentioned a difficulty: they admitted there are seriously affected by Chinese traditional philosophy. At the core of Chinese traditional philosophy is "the doctrine of the golden" which means always keep neutral, or "the less trouble the better". These five interviewees believe in traditional philosophy mentioned before. When anything unusual or suspicious related to fraud found, their first idea in mind is always not to detect or report that. They prefer to keep slice for a while to observe the situation whether any other team member perceive the potential fraud. Two interviewees admitted that in their audits of listed companies, they did not want to meet then detect and report any corporate fraud or tried to stay away. Five of the interviewees expressed the opinion that this doctrine makes it difficulty for Chinese auditors to play their rightful role in detecting and reporting corporate fraud.

\subsubsection{Responses to Question (3)}

In answering Question (3), all of the interviewees expressed that the external auditors of listed companies do have responsibilities in detecting and reporting corporate fraud. However, six of the interviewees who are current auditors or assistant auditors of listed companies said that they are not clear with the responsibilities specified in relevant laws, regulations and professional standards. $\mathrm{L}_{1}, \mathrm{~L}_{2}, \mathrm{~L}_{3}$, and $\mathrm{L}_{4}$ admitted that a further factor limiting Chinese auditors' ability in detecting and reporting corporate fraud is their lack of understanding of CSA 1141. They conveyed CSA 1141 has still not been fully incorporated in the work of auditors in local firms although it is nearly 3 years since the new auditing standards took effect in 1st January 2007. In exploring the reasons, seven of the interviewees explained that the work habits of auditors in the local firms result from apprenticeships being the common means in local firms to cultivate new staff instead of by providing them with systematic training. All of these seven interviewees have a master teaching them during the ordinary work initially. L3 has several apprentices right now and explained that the shortage of CPAs results in 'learning by doing' under the guidance of older auditors becoming the main way of new auditors becoming acquainted with the requirements of auditing standards. However, the older auditors are unfamiliar with the new standards.

Although in China, practicing CPAs are required to participate in a CPD program for a total of 80 hours each 2 years, with a minimum of 30 hours in each year (World Bank, 2009). All the interviewees with CPA qualification admitted that they have a negative attitude towards CPD, and further admitted that they had not attended to the CPD program. In spite of this requirement is mandatory, they pointed out that in CPAs Law, absence of the CPD program will not affect the qualification. That is their certificate of CPA will not be revoked. Additionally, $\mathrm{F}_{1}$ said there is no evaluation system of the CPD program so the quality can not be guaranteed. Three of the interviewees even expressed that they were not confident about the quality of CPD programs because the CPD programs usually poor organized.

\subsubsection{Responses to Question (4)}

In answering Question (4), $\mathrm{L}_{1}$ reported that during each audit the audit engagement partners reminded audit team members to maintain their professional skepticism and note any indication of possible fraud. However, during the audit 
process, local auditors focused on detailed audit tests rather than on risk assessment. $B_{2}$ suggested that in the international firms, the reverse was the case, that is, the auditors placed greater emphasis on procedures such as risk assessment rather than on detailed audit tests which is against with the requirements of CAS 1141. As a result, five of the interviewees identified the implement of auditing standards as the main difference between local and international firms. And they conveyed that this difference form a difficulty to Chinese external auditors to perform their role in detecting corporate fraud.

\subsubsection{Responses to Question (5)}

In answer to Question (5), all the interviewees stressed the importance of education: not only the professional education but also the citizenship education. Six interviewees identified citizenship education as an important method to change traditional ideas. People involved in audits of listed companies should not place relationships high on their list of priorities. Four interviewees said this kind of overemphasis which significantly blocks the role of external auditors in detecting and reporting fraud can be overcame by citizenship education.

Three of the interviewees suggested reducing the regulators. Once corporate fraud reported, their firms will receive a series of examinations, investigations and inquiries. This will add extra cost to the report of corporate fraud.

Several difficulties were identified in this chapter including the independence of external auditors, the implement of CSA 1141 and special difficulties due to traditional culture factors.

\section{Conclusions and Recommendations}

\subsection{Recommendations}

\subsubsection{Reformation of Regulation Model of the CPA profession}

The regulation model of the CPA profession needs to be reformed so that the government control is relaxed gradually and removed finally. In order to achieve this aim, the CPAs Laws needs to be revised to redefine the status of CICPA. As the only professional accounting association in China, the CICPA needs to be autonomous. The CICPA should freely work instead of under the lead of MOF. The charter of the CICPA also should be modified so that the leaders of the CICPA should be ejected by a National Assembly of Delegates or even all members of CICPA. The CICPA should have the sole right to admit applicants to membership and, if they have good grounds to do so, to cancel a CPA's membership. Additionally, the CICPA should be empowered to have authority monitoring the work of its members- especially the external auditors- and taking actions where defective work is found. The regulators including financial department and audit authority should unite to form an oversight agency. The CICPA should report their work to this oversight agency on regular tome-basis instead of approving by the MOF. This oversight agency can investigate the work of the CICPA rather to investigate the accounting firms directly. As a result, the self-regulation model will set up under an oversight agency.

\subsubsection{Independence Maintained}

The accounting firms should take measures to keep independence both substantially and formally. Accounting firms should adopt a strategic of obtaining their competitive advantage by improving their audit quality rather than depending on personal relationships to get clients. At the same time the firms should actively improve their internal governance by developing a promotion and reward system which emphasizes on integrity, teamwork, knowledge, diligence and self-discipline.

\subsubsection{Continuous Professional Development}

Various measures should be taken to ensure qualified CPAs maintain their professional knowledge by attending high level of CPD programs. The current situation should be changed for this is not a something that can be completed once for all. Currently, there are three national accounting institute (NAIs) established by the central government and five universities under the authority of MOF. From the regional distribution, they can cover all over the country. The major participants of the NAI program include senior financial managers of state-owned enterprises and medium-size enterprises as well as CPAs. They have pretty high quality standards for professional continuing education. The CPAs would like to attend this kind of high level training for their development of career. From a short-term point of view, the MOF will still be the main regulator of CPA profession. Consequently, the MOF together with NAIs and affiliated universities should offer high quality post-professional education and training to CPAs. At present, the CPD should focus more on the implementation of new auditing standards so as to maintain sufficient knowledge and professional skills.

Meanwhile, the CICPA and its local organizations should be in charge of the CPD programs. They should carry on inspection of the training quality and monitor the attendance rate. Additionally, the CPAs should be required to attend an 
evaluation system after their CPD programs. Because of the lack of driving force, CPD becomes a mere formality gradually. The CPAs Law should be revised to add a mandatory requirement for CPAs to maintain their qualification by completing an evaluation system. A new evaluation system should be introduced into the update of their professional knowledge and practical skills. The system should be consisted of two parts. One is a regular exam after the periodic CPD program. The CICPA should design and check the examination papers. As well the CICPA should set up a standard for the examinations. And any CPA who fails in the exam more than certain times would lose his qualification. The other is the selective check of their daily work. The qualification of CPAs who failed to meet the sound mechanism would be canceled by the CICPA.

\subsection{Contribution, Limitation and Opportunities for Further Research}

Based on the research, this study makes some recommendations on how auditors in China might, more effectively, detect and report corporate fraud of listed companies. This will strengthen the role of the auditors of Chinese plcs to be more effective in detecting and reporting corporate fraud. As a consequence, this will be helpful to improve the quality of external auditing in China. This should help to ensure the reliability of financial information provided by Chinese plcs for investors. At the same time, this will force Chinese plcs to improve their level of corporate governance.

Notwithstanding its potential contribution, the study has limitations. In particular, the views emerged in eight semi-structured interviews may not be comprehensive enough to represent the opinions of auditors of plcs in China in general due to the very small number of interviews. Additionally, both economic development and external auditing is occurring at a very rapid pace under the unceasingly changed economic environment in China. The actual situation of listed companies and accounting firms keep changing. As a consequence, the findings of this study may apply only for a limited period of time.

Meanwhile, more semi-structured interviews can be added to the sample. More representative interviewees can be selected to conduct the interviews. So that more information about the practical difficulties facing the Chinese auditors of listed companies in detecting and reporting corporate fraud can be collected and analyzed. Thus, recommendations more appropriate and with greater pertinence can be made to Chinese auditors.

\section{References}

Chen, L. \& Lin, W. (2007). Corporate governance and fraud: evidence from China. Corporate ownership and control. 4(3), 139-145.

China Securities Regulatory Commission (CSRC). (2008). China capital markets development report. Beijing: CSRC.

Chinese Institute of Certified Public Accountants (CICPA). (1999). The Chinese Public Accountancy Profession Towards the 21st Century. Beijing: China Pictorial Publishing House..

Chinese Institute of Certified Public Accountants (CICPA). (1999b), The Development Process of the Chinese CPA profession (I)(in Chinese), The Chinese Certified Public Accountant, 3,10-12.

Chinese Institute of Certified Public Accountants (CICPA). (2001). Brief News (in Chinese). The Chinese Certified Public Accountant. 5,48.

Chong, G. (1999). The auditing systems in the People's Republic of China. Journal of Accounting and Auditing.43(4), 281-285.

Chong, G. (2000). Auditing framework in the People's Republic of China and the International Auditing Guidelines: some comparisons. Managerial Finance. 26(5).12-20.

Chow, L. M. Chau, G. K. Gray, S. J. (1995). Accounting reforms in China: Cultural constraints on Implementation and Development. Accounting and Business Research. 26(11),29-49.

Cooper, B. J., Chow, L. \& Tang, Y. W. (2002) The Development of Auditing Standards and the Certified Public Accounting Profession in China. Managerial Auditing Journal. 17(7), 383-389. http://dx.doi.org/10.1108/02686900210437480

Dai, X. (2000). Hooking-up: a unique feature of China public accounting firms. Managerial Finance.26(5), 21-30. http://dx.doi.org/10.1108/03074350010766657

Davidson, R. A. (2003). The importance of auditing topics to Chinese auditors. International journal of auditing. 12(2), 77-90.

DeFond. M. L., Wong, T. J. \& Li, S. (2000). The impact of improved auditor independence on audit market 
concentration in China. Journal of Accounting and Economics.28, 269-305. http://dx.doi.org/10.1016/S0165-4101(00)00005-7

Edwards, J. R. (2001), Accounting Regulation and the Professionalization Process: An Historical Essay Concerning the Significance of P.H. Abbott. Critical Perspectives on Accounting. 12,(6), 675-696. http://dx.doi.org/10.1006/cpac.2000.0453

Ferdinand, A. G., Heibatollah, S. \& Zhou, H. (2009). Auditor Disaffiliation Program in China and Auditor Independence. A Journal of Practice \& Theory. 28(1), 29-51.

Firth, M., Mo, L. L. \& Wong, M. K. (2005). Financial Statement Frauds and Auditor Sanctions: An Analysis of Enforcement Actions in China. Journal of Business Ethics.62(4),367-381. http://dx.doi.org/10.1007/s10551-005-0542-4

International Auditing and Assurance Standards Board (IAASB). (2006). International Standard on Auditing (ISA): 240: The auditor's responsibilities relating to fraud in an audit of financial statements. New York: IFAC.

Jia, C., Ding, S., Li, X. \& Wu, Z. (2009). Fraud, enforcement action, and the role of corporate governance: evidence from China. Journal of Business Ethics.79(3), 561-576. http://dx.doi.org/10.1007/s10551-009-0061-9

Johnston, G.., Parker, C. (2007). Auditors’ liability in China. A Plus. 6, 36-39.

Kuan, I. C. \& Noronha, C. (2007). The progress of accounting harmonization in China. Managerial Audit Journal. 22(6), 620-640. http://dx.doi.org/10.1108/02686900710759415

Lin, K. Z. (2008). Auditors' ability to resist client pressure and culture: perception in China and the United Kingdom. Journal of International Financial Management and Accounting. 13(22), 65-80.

Lin, W. T. (2004). Corporate governance in China: recent developments, key problems, and solutions. Journal of Accounting and Corporate Governance. 1, 1-23.

Lin, Z. J. \& Chen, F. (2004). An empirical study of audit 'expectation gap' in The People's Republic of China. International Journal of Auditing. 8(2), 93-115. http://dx.doi.org/10.1111/j.1099-1123.2004.00084.x

Ma, X. M. \& Zheng, C. H. (2006). Top 10 financial fraud of public listed companies in 2005. Auditor Digest.4, 76-77.

National Accounting Institute (NAI) Financial Fraud Research Center (FFRC). (2006). Top 10 financial fraud of public listed companies in 2005. Shanghai: NAI.

National Accounting Institute (NAI) (2003) No Fictitious Records and Accounting Integrity. Shanghai: NAI.

Shanghai Stock Exchange (SSE). 2003. China Corporate Governance Report (2003). Shanghai: SSE.

Shanghai Stock Exchange (SSE).2003. The Report of Corporate Governance.Shanghai: SSE.

Shanghai Stock Exchange (SSE). (2009). Shanghai Stock Exchange Statistics Annual. Shanghai: SSE.

Shenzhen Stock Exchange (SZSE). (2009). Shenzhen Stock Exchange fact book 2008. Shenzhen: SZSE.

World Bank. (2009). Report on the Observance of Standards and Codes (Rosc)- Accounting and Auditing. Tokyo: World Bank.

Xiao, J., Zhang, Y. \& Xie, Z. (2000). The making of independent auditing standards in China. Accounting Horizon.14(1),69-89. http://dx.doi.org/10.2308/acch.2000.14.1.69

Xuan, Y. (2002). Why Did CPAs Involve in Listed Companies Falsification Whirlpool. The CICPA Journal. 2,24-26(in Chinese).

Yang, J. W. \& Yang, J. L. (1998). The Handbook of Chinese Accounting. Hong Kong: Oxford University Press.

Yang, L. (2003). Auditor independence issues in China. Managerial Finance. 29(12), 57-64. http://dx.doi.org/10.1108/03074350310768643

Yang, L., Tang, A. \& Jiang, Y. (2001). Auditor-government associations and auditor independence in China. The British Accounting Review.33 (2),175-189. http://dx.doi.org/10.1006/bare.2001.0162 
Table 1. Accounting firms and affiliations

\begin{tabular}{|c|c|}
\hline CPA firm & Affiliation \\
\hline Shanghai & Finance Bureau of Shanghai \\
\hline Zhonghua SASS & Ministry of Finance and Shanghai Academy of Social Sciences(SASS) \\
\hline Dahua & Shanghai University of Finance and Economics \\
\hline Li-hsing & Li-hsing Accounting College \\
\hline Shanghai Shangrui & Taxation Bureau of Shanghai \\
\hline Shanghai Datong & Metallurgical Industry Bureau of Shanghai \\
\hline Shanghai Zhongchuang & Office of Finance and Trade, Communist Party Committee of Shanghai \\
\hline
\end{tabular}

Source: Dai, 2000

Table 2. The profiles of the interviewees in the semi-structured interviews

\begin{tabular}{|c|c|c|c|c|c|}
\hline & $\begin{array}{c}\text { Qualified } \\
\text { CPA }\end{array}$ & $\begin{array}{l}\text { Current auditor or } \\
\text { assistant of Chinese } \\
\text { listed company }\end{array}$ & $\begin{array}{c}\text { Experience in audits of } \\
\text { Chinese listed } \\
\text { companies }\end{array}$ & $\begin{array}{l}\text { Holder of } \\
\text { university } \\
\text { degree }\end{array}$ & $\begin{array}{l}\text { Career } \\
\text { time } \\
\text { (Years) }\end{array}$ \\
\hline $\mathrm{L}_{1}$ & 0 & 0 & 0 & 0 & $>2$ \\
\hline $\mathrm{L}_{2}$ & 0 & 0 & 0 & 0 & $<1$ \\
\hline $\mathrm{L}_{3}$ & 0 & 0 & 0 & 0 & $>10$ \\
\hline $\mathrm{L}_{4}$ & $x$ & 0 & 0 & 0 & $<1$ \\
\hline $\mathrm{B}_{1}$ & 0 & 0 & 0 & 0 & $>5$ \\
\hline $\mathrm{B}_{2}$ & 0 & 0 & 0 & 0 & $>3$ \\
\hline $\mathrm{F}_{1}$ & 0 & $x$ & 0 & 0 & $>3$ \\
\hline $\mathrm{F}_{2}$ & $x$ & $x$ & 0 & 0 & $<1$ \\
\hline
\end{tabular}

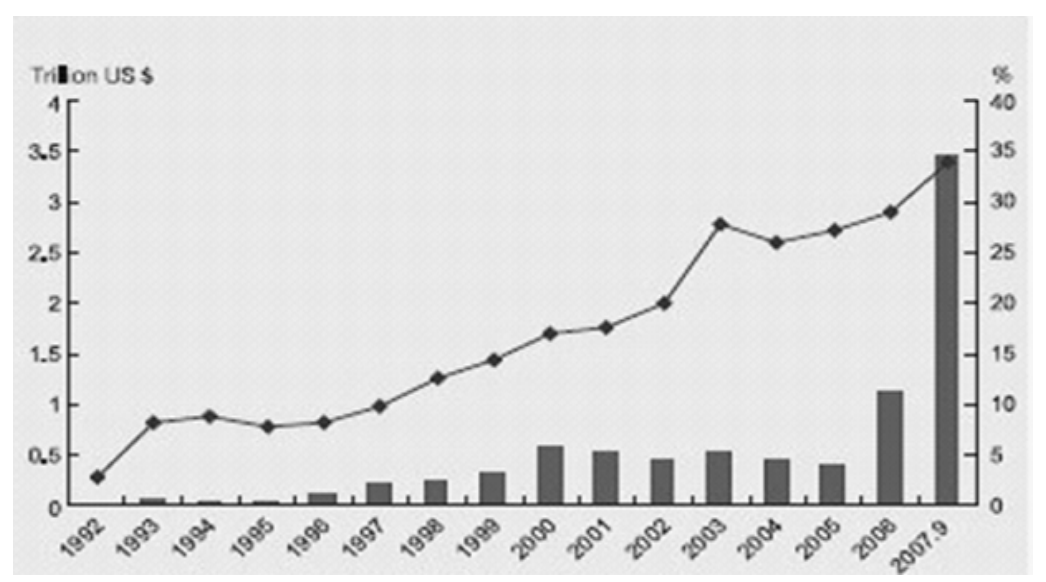

Figure 1. Total market capitalizations and operating income of core business of listed companies as percentage of GDP

Market Capitalization (Trillion US\$)

Operating Income/GDP (\%)

Source: CSRC and China Securities and Futures Statistical Yearbook, 2007.

Note: 2007 data is based on the report of listed companies before September. 


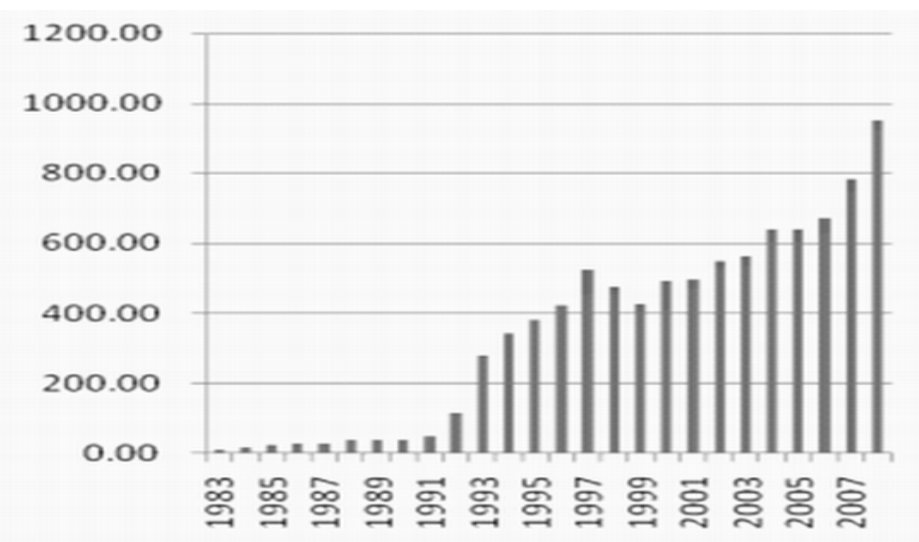

Figure 2 Foreign investments in China 1983-2008

Foreign investment (Billion US\$)

Source: National Bureau of Statistics (NBS), 2009

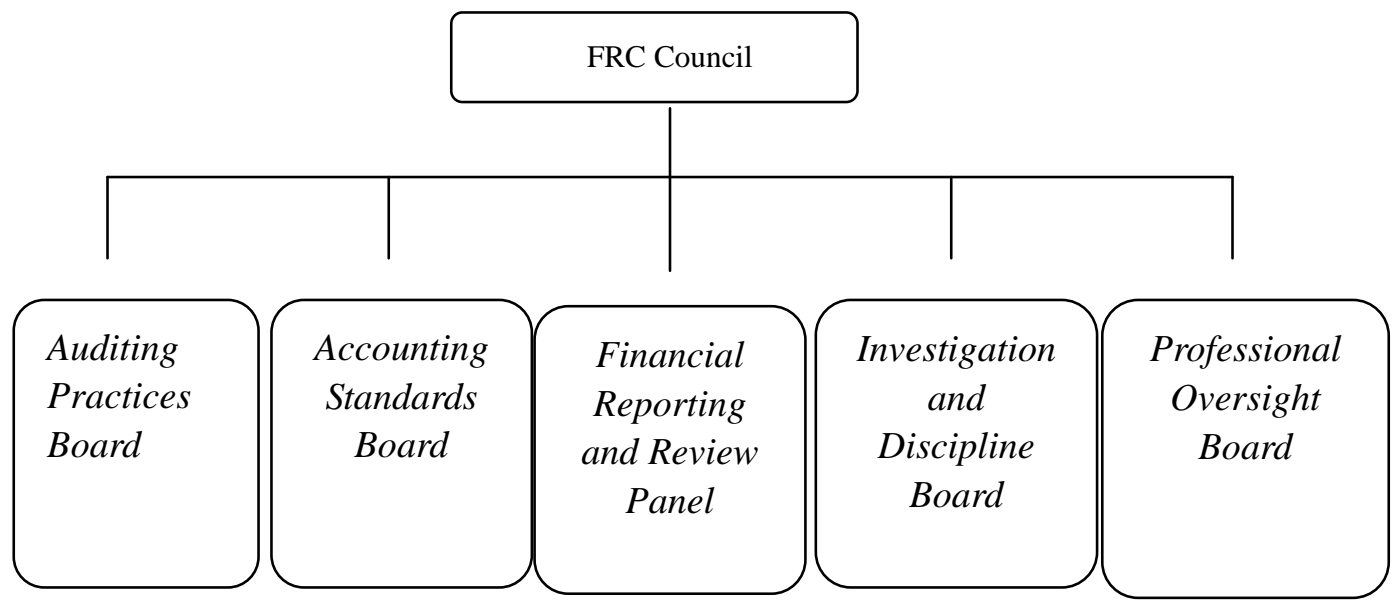

Figure 3. The structure of New FRC

Source: FRC, 2010 